\title{
Implikasi konsep heutagogi dalam pendidikan Islam kontemporer
}

\author{
Ulil Amri Syafri'1, Rahendra Maya ${ }^{2}$ \& Amie Primarni ${ }^{3}$ \\ ${ }^{1}$ Sekolah Pascasarjana Universitas Ibn Khaldun (UIKA) Bogor \\ ${ }^{2}$ Sekolah Tinggi Agama Islam (STAI) Al Hidayah Bogor \\ ${ }^{3}$ Pascasarjana Institut Agama Islam (IAI) Nasional Laa Roiba Bogor \\ ulilamri.syafri@uika-bogor.ac.id
}

\begin{abstract}
This article aims philosophically-conceptually to identify the educational implications of the concept of heutagogy in contemporary Islamic education, especially in the era of 4.0 which demands learning and acquiring knowledges and skills effectively and efficiently so that learners have adaptive and innovative advantages. As a continuum that does not stand alone with the concepts of pedagogy and andragogy, especially as a continuation of andragogy; the concept of heutagogy which is in line with the concept of Islamic education is a model of independent learning or learning by/for himself as a learner. This research is a qualitative research with descriptive method. Based on the results of the discussion of the educational implications of heutagogy in contemporary Islamic education, including the determination of spirit ('uluww al-himmah) in learning (thalab al-'ilm), lifelong learning (alta'allum madâ al-hayâh), educational awareness, and integration of heutagogy into the concept of pedagogy-andragogy.
\end{abstract}

Keywords: heutagogy, learning, self-independent learning.

\begin{abstract}
Abstrak
Artikel ini bertujuan secara filosofis-konsepsional untuk mengidentifikasi implikasi edukatif dari konsep heutagogi dalam pendidikan Islam kontemporer, khususnya di era 4.0 yang menuntut pembelajaran serta pemerolehan ilmu pengetahuan dan keterampilan secara efektif dan efisien agar pembelajarnya memiliki keunggulan yang adaptif dan inovatif. Sebagai suatu kontinum yang tidak berdiri sendiri dengan konsep pedagogi dan andragogi, terutama sebagai kelanjutan dari andragogi; konsep heutagogi yang selaras dengan konsep pendidikan Islam merupakan model pembelajaran mandiri atau pembelajaran oleh/untuk diri sendiri seorang pembelajar. Penelitian ini merupakan penelitian kualitatif dengan metode deskriptif. Berdasarkan hasil pembahasan implikasi edukatif heutagogi yang dalam pendidikan Islam kontemporer meliputi tekad baja ('uluww al-himmah) dalam belajar (thalab al-'ilm), belajar sepanjang hidup (life long learning, alta'allum madâ al-hayâh), kesadaran pendidikan, dan integrasi heutagogi ke dalam konsep pedagogi-andragogi.
\end{abstract}

Kata Kunci: heutagogi; pembelajaran; kemandirian belajar.

Diserahkan: 07-02-2021 Disetujui: 02-03-2021. Dipublikasikan: 05-03-2021

Kutipan: Syafri, U. A., Maya, R., \& Primarni, A. (2021). Implikasi konsep heutagogi dalam pendidikan Islam kontemporer. Ta'dibuna: Jurnal Pendidikan Islam, 10(1), 45-56.

doi:http://dx.doi.org/10.32832/tadibuna.v10i1.4249 


\section{Pendahuluan}

Belum begitu lama, Kementerian Pendidikan dan Kebudayaan (Kemendikbud) yang dipimpin oleh Nadiem Makarim mengeluarkan berbagai kebijakan yang oleh sebagian pihak dinyatakan revolusioner. Salah satunya adalah program "Merdeka Belajar" dengan moto "Merdeka Belajar, Guru Penggerak".

Selain sebagai kebijakan baru yang kerap menuai pro-kontra, kebijakan revolusioner tersebut dinilai baru sebatas wacana konseptual yang belum terarah dan masih ditunggu program-program aplikatifnya. Terlebih lagi ketika wabah pandemik global COVID-19 melanda, di mana pembelajaran dan proses pendidikan dilakukan secara daring atau populer diistilahkan sebagai Pembelajaran Jarak Jauh (PJJ).

Akhir-akhir ini, kebijakan PJJ justru menuai protes yang cukup keras, terutama setelah berlangsung selama empat bulanan hingga permulaan tahun ajaran baru pada 2020/2021 ini. Dalam beberapa penelitian misalnya, diungkapkan bahwa PJJ memberikan dampak dan pengaruh sekaligus tantangan dan hambatan, antara lain murid yang merasa dipaksa belajar jarak jauh tanpa sarana dan prasarana memadai di rumah serta berkaitan dengan kesiapan sumber daya manusia, arahan pemerintah yang kurang jelas, dan belum adanya kurikulum PJJ yang tepat (Purwanto, dkk., 2020, hlm. 8; Abdul Latip, 2020, hlm. 108).

Berkaitan dengan hal tersebut, pembelajaran atau belajar sendiri banyak didefinisikan sebagai "perubahan perilaku (performance) yang relatif permanen, sebagai hasil latihan atau pengalaman dan bukan karena pertumbuhan atau kelelahan atau karena obat-obatan" (Mulyadi, Basuki \& Rahardjo, 2017, hlm. 36).

Hingga kini, belajar dikategorikan sebagai sesuatu yang selalu melekat pada dan tidak bisa lepas dari kehidupan manusia sekaligus menjadi atributnya yang membedakannya dengan makhluk hidup lainnya yang ada di muka bumi. Manusia sebagai makhluk berpikir yang dapat dididik (animal educabile) dan harus dididik (animal educandum) sekaligus sebagai makhluk yang dapat mendidik (homo educandus) (Bunyamin, 2010, hlm. 261).

Dalam perspektif Ilmu Pendidikan Islam (Ramayulis, 2015, hlm. 12-13), kebutuhan manusia terhadap pendidikan dan belajar berawal dari konsepsi dan prinsip dasar tentang manusia. Di antaranya (1) karena manusia adalah makhluk materi dan imaterial yang membutuhkan proses pembinaan kedua komponen tersebut secara integratif; (2) karena manusia adalah makhluk yang mampu berbahasa, berpikir, dan bermasyarakat yang harus mengembangkan kemampuannya tersebut; dan (3) karena manusia adalah makhluk yang mengabdikan diri kepada Allah dan menjadi khalîfah-Nya, maka Allah membekalinya dengan berbagai potensi agar dapat melakukan tugasnya secara totalitas. 
Di mana proses belajar melalui pendidikan tersebut berlangsung seumur hidup atau sepanjang kehidupannya (life long education) yang telah dikembangkan sejak zaman Nabi Muhammad (Hasbullah, 2017, hlm. 73-74).

Proses belajar tersebut pada umumnya diimplementasikan pada kegiatan pendidikan dan proses pembelajaran yang di dalamnya terdapat pendidik dan peserta didik sebagai objek utama pendidikan. Oleh karena itu, berdasarkan karakteristiknya tersebut, manusia merupakan makhluk yang selalu terlibat dalam proses pendidikan, baik yang diberlakukan terhadap dirinya sendiri maupun dilakukan terhadap orang lain.

Selama ini, setidaknya secara umum dan berdasarkan paradigma yang paling populer, term pendidikan dan hakikat substansial yang menjadi ciri khasnya sering diistilahkan secara sepadan dengan istilah pedagogi dan andragogi. Pedagogi selain dipahami sebagai cara belajar anak-anak, juga dinyatakan sebagai hubungan antara guru dan murid yang berpusat pada guru (teacher learned). Sedangkan andragogi dipahami sebagai cara belajar atau pembelajaran orang dewasa yang dapat menentukan sendiri prosesnya (apa dan bagaimana belajar, student learned) (Danim, 2015, hlm. 144-145).

Pedagogi dan andragogi disimpulkan (Marzuki, 2012, hlm. 167) secara distingtif sebagai "anak belajar yang dipandang sebagai proses pembentukan, perolehan (acquiring), pengumpulan (accumulating), penemuan (discovering), dan pemaduan (integrating) pengetahuan, skills, strategi, dan nilai-nilai yang diperoleh dari pengalaman. Sedangkan orang dewasa belajar dipandang sebagai transformasi, yaitu mengubah (modifying), mempelajari kembali (relearning), memperbarui (up grading), dan mengganti (replacing)".

Di samping kedua konsep dasar pembelajaran tersebut, ada sebuah konsep pembelajaran diri yang juga merupakan hasil pengembangan dari pembelajaran orang dewasa (andragogi) yang disebut heutagogi. Konsep pembelajaran ini konon termasuk model pembelajaran yang belum banyak dikenal terlebih untuk diimplementasikan dalam proses pembelajaran saat ini.

Heutagogi merupakan studi tentang pembelajaran -baik oleh anak-anak maupun orang dewasa- yang ditentukan secara mandiri dengan berbasis kepada potensi dan kesadaran diri secara bertanggung jawab (Danim, 2015, hlm. 145). Yaitu (Mulyadi, Basuki, dan Rahardjo, hlm. 36) "kesadaran seseorang tentang proses kognisi mereka sendiri dan bagaimana proses itu bekerja (awerness of their own cognitive machinery and how the machinery works)", yang dinyatakan sebagai metakognitif.

Walaupun ketiga term pendidikan atau konsep pendidikan tersebut sudah muncul cukup lama, namun term heutagogi dianggap masih kalah pamor dan kurang populer dibandingkan dua term lainnya, termasuk dalam berbagai kajian, baik dalam studi 
penelitian-akademik, artikel prosiding/jurnal, buku populer, maupun dalam karya tulis lainnya.

Dalam kajian dan penelitian telah banyak dinyatakan bahwa konsep pedagogi dan andragogi bersesuaian dengan ajaran Islam, terutama bersesuaian dengan ayat-ayat AlQur'an dan teks-teks hadis serta pemikiran para ulama terutama para pakar pendidikan Islam. Demikian pula halnya dengan heutagogi, terlebih heutagogi sendiri merupakan kontinum atau kelanjutan yang tidak dapat berdiri sendiri dari konsep andragogi.

Dalam Disertasi Rosidin yang kemudian diterbitkan menjadi sebuah buku dengan judul Konsep Andragogi dalam Al-Qur'an (2013, hlm. 253-289), dideskripsikan tentang hubungan konsep andragogi dalam Al-Qur'an dengan teori andragogi. Hubungan tersebut meliputi hubungan similarisasi atau paralelisasi, konfirmatif, komplementasi, informatif, dan korektif.

Menarik dicermati, hubungan korektif yang dimaksud bahwa konsep andragogi dalam Al-Qur'an mengoreksi pandangan-pandangan teori andragogi yang dinilai lemah atau memiliki kekurangan. Antara lain berkaitan dengan prinsip dasarnya yang meliputi kebutuhan pengetahuan (the need to know), konsep diri pembelajar (the learner's self concept), peran pengalaman pembelajar (the role of learner's experience), kesiapan belajar (readiness to learn), orientasi belajar (orientation to learning), dan motivasi (motivation).

Sedangkan dalam Disertasi Mohammad Al Farabi (2018, hlm. 289-317) yang telah diterbitkan pula menjadi sebuah buku dengan judul Pendidikan Orang Dewasa dalam AlQur'an, disimpulkan bahwa konsep andragogi dalam Al-Qur'an memiliki relevansi dengan dunia pendidikan Islam kontemporer berkaitan dengan prinsip-prinsip dasar pendidikan orang dewasa, kesiapan belajar orang dewasa, konsep belajar melalui pengalaman, pelibatan peran orang dewasa dalam pendidikan, dan komunikasi pada pendidikan orang dewasa.

Penelitian kali ini bertujuan untuk mengidentifikasi implikasi edukatif dari konsep heutagogi dalam pendidikan Islam kontemporer secara filosofis-konsepsional, khususnya di era 4.0 .

\section{Metode Penelitian}

Penelitian ini merupakan penelitian kualitatif dengan metode deskriptif. Objek yang diteliti adalah konsep heutagogi yang diambil dari berbagai penelitian mengenai heutagogi. Data-data tersebut kemudian dikaitkan dengan pendidikan Islam sehingga menghasilkan implementasi dalam pendidikan Islam kontemporer. 


\section{Hasil dan Pembahasan}

\section{A. Konsep heutagogi}

Heutagogi (heutagogy) merupakan konsep pendidikan dan pembelajaran yang pertama kali diciptakan dan dipopulerkan oleh Stewart Hase dari Southern Cross University (Danim, 2015, hlm. 143). Heutagogi berasal dari bahasa Yunani yang oleh Hase dan Chris Kenyon (Khoeriyah, 2019, hlm. 74) didefinisikan sebagai pembelajaran mandiri atau pembelajaran yang ditentukan oleh diri sendiri (self-determited learning/independent).

Heutagogi adalah kombinasi dari kata hauto yang berarti "diri" dan agogos yang berarti "memimpin atau membimbing". Secara harfiah, heutagogi dapat diartikan sebagai ilmu atau seni mengajar diri sendiri. Jadi heutagogi adalah ilmu untuk memimpin atau membimbing diri sendiri (Subbekan, 2019, hlm. 21).

Oleh karena itu, heutagogi secara simplistis dapat didefinisikan atau dinyatakan sebagai pembelajaran mandiri atau pembelajaran oleh dan untuk diri sendiri.

Heutagogi merupakan studi tentang belajar yang ditentukan oleh diri pembelajar sendiri. Heutagogi berpusat pada perbaikan belajar cara belajar, dua keluk belajar, kesempatan belajar universal, proses non-linier, dan arah sejati diri pembelajar. Heutagogi mensyaratkan inisiatif pendidikan termasuk peningkatan keterampilan (Mariah H., 2015, hlm. 22-23).

Sebagai pengembangan dari andragogi (pembelajaran orang dewasa), heutagogi tentu memiliki beberapa sisi kesamaan dengan andragogi. Perbedaannya dengan andragogi adalah dalam andragogi masih terdapat peran antara guru dan siswa atau antara peserta dan fasilitator. Dalam heutagogi peran itu sudah lebur, karena dua pihak atau lebih dalam pembelajaran secara bersama-sama menjadi pembelajar. Pihak-pihak yang terlibat saling menimba ilmu dan saling belajar dengan yang lain. Peran guru/fasilitator tidak sebatas sebagai pemberi ilmu, tetapi perannya lebih dari itu yaitu sebagai pembelajar sepanjang hayat, pemimpin pembelajaran, pengarah sumber belajar, pengarah pembentuk jaringan, manajer keberagaman jaringan, dan pembuka komunikasi. Intinya keduanya sama-sama menjadi pembelajar (Sulistya, 2019, hlm. 133).

Danim (2015, hlm. 143-148) menyimpulkan bahwa titik tekan heutagogi khusus pada perbaikan belajar cara belajar, dua keluk belajar (double loop learning), kesempatan belajar universal, proses non-linear, dan arah sejati diri pembelajar. Berikut penjelasan dari prinsip dasar heutagogi tersebut:

a. Heutagogi mensyaratkan bahwa inisiatif pendidikan berasal dari masyarakat atau diri pembelajar sendiri, sehingga pembelajar sendiri yang menentukan apa dan bagaimana belajar itu harus dilakukan. 
b. Setiap orang memiliki keinginan untuk belajar dan kecenderungan alami untuk melakukannya sepanjang hidup, tanpa perlu berdebat pada konsep pedagogi ataukah andragogi.

c. Kelukan atau simpulan belajar ganda (double loop learning); merupakan proses belajar yang berfokus pada "belajar bagaimana belajar" dan "belajar untuk apa". Yaitu konsep belajar yang menawarkan tentang bagaimana orang belajar, menjadi kreatif, memiliki efektivitas diri tingkat tinggi, dapat menerapkan kompetensi dalam situasi kehidupan, dan dapat bekerja secara baik dengan orang lain.

d. Adaptasi manusia, maksudnya heutagogi menantang cara berpikir pembelajar tentang "belajar dan belajar", mendorong guru berpikir pada proses ketimbang isi, memungkinkan pembelajar lebih memahami dunia mereka daripada dunia gurunya, memaksa guru pindah ke dunia pembelajar, serta memungkinkan guru untuk melihat melampaui disiplin mereka sendiri dan teori-teori favorit.

\section{B. Implikasi Edukatif Konsep Heutagogi}

Oleh karena itu, implikasi konsep heutagogi dalam pendidikan Islam kontemporer spesifiknya di era 4.0 setidaknya dapat dikemukakan sebagai berikut:

\section{Tekad Baja ('Uluww Al-Himmah) dalam Belajar (Thalab Al-'Ilm)}

Selain motivasi ekstrinsik yang berasal dari dan terpengaruh oleh faktor luar, motivasi intrinsik merupakan kunci dalam belajar dan dalam mengikuti atau melakukan pembelajaran, terutama secara mandiri dan untuk diri sendiri yang setiap saat pastilah membutuhkan pemicu dan pemacu diri untuk memantik semangat belajar.

Menurut Muhammad ibn Mathr Al-Zahrânî (2005, hlm. 19-31), bahwa asas utama dari konsep belajar (asas manhaj thalab al-'ilm) dalam Islam terdiri dari empat pilar, yaitu:

a. Niat, motivasi atau spirit sebagai proses awal belajar (awwal al-'ilm al-niyyah).

b. Tahapan atau proses belajar (manâzil al-'ilm).

c. Adab atau etika sebelum belajar (al-adab qabl al-thalab).

d. Mengaplikasikan hasil belajar melalui kerja nyata dalam bentuk pengamalan aplikatif (iqtirân al-'ilm bi al-'amal).

Dalam Islam, niat, motivasi, semangat, dan cita-cita yang tinggi (atau motivasi intrinsik) bahkan dinyatakan sebagai langkah pertama dalam belajar (awwal al-'ilm alniyyah) serta sangat didorong untuk dimiliki oleh seorang pembelajar dengan penuh keikhlasan dan semangat tinggi (Al-'Askarî, dkk, 1412 H.).

Niat sebagai motivasi intrinsik tersebut dalam kajian ulama selanjutnya dideskripsikan sebagai tekad, semangat atau cita-cita (al-himmah); di mana yang dituntut dari seorang pembelajar adalah tekad yang kuat, semangat yang bergelora atau cita-cita yang tinggi. Dalam kajian para ulama motivasi intrinsik tersebut diungkapkan sebagai al- 
himmah al-'âliyah atau 'uluww al-himmah, bukan yang rendah yaitu al-himmah aldâniyah atau dunuww al-himmah (Maya \& Syafri, 2020, hlm. 245-248).

Muhammad ibn Ismâ'îl Al-Muqaddam (t.t., hlm. 7-8) mendefinisikan al-himmah al'âliyah atau 'uluww al-himmah sebagai motivasi intrinsik yang menjadi pendorong lahirnya sebuah aktivitas (al-bâ'its 'alâ al-fi't); permulaan sebuah tekad (awwal al-'azm); kekuatan tekad jiwa untuk mengerjakan sesuatu sebelum memulainya ('aqd al-qalb 'alâ fi'l syai' qabla an yaf'ala); atau (Al-'Affânî, 1997, hlm. 1/11) mengendalikan jiwa dan kehendaknya dengan cara mengoptimalkan pelbagai kekuatan rohaninya dalam mendapatkan kebaikan yang sempurna baik bagi dirinya sendiri maupun bagi orang lain yang dibantunya (tawajjuh al-qalb wa qashdihi bi jamî' quwâhu al-rûhâniyyah ilâ jânib alhaqq li hushûl al-kamâl lahu au li ghairihi), tentunya yang dimaksud adalah dalam kebaikan dan kemuliaan, termasuk dalam belajar.

Sedangkan menurut Muhammad bin Ibrahim Al-Hamad (2014, hlm. 17), yang dimaksud dengan cita-cita yang tinggi (al-himmah al-'âliyah) adalah niat yang tulus, tekad yang bulat, kemauan yang keras, dan keinginan yang kuat untuk menghiasi diri dengan hal-hal yang terpuji dan melepaskan diri dari perkara-perkara yang tercela.

Tekad baja dalam belajar yang dilakukan kaum muslimin dalam rekaman faktual sejarah yang berhasil dihimpun oleh 'Ali ibn Muhammad Al-'Imrân (1422 H.) dan Raghib Al-Sirjani (2016, hlm. 175-355) antara belajar melalui proses menghafal, berguru, mengembara, membaca, menulis, menyalin, dan menyusun karya ilmiah. Mereka menghafal dan membaca ratusan kitab serta menulis puluhan bahkan hingga ratusan karya ilmiah. Itulah spirit berliterasi kaum muslimin yang par excellence hingga melahirkan peradaban ilmiah yang luar biasa dan dapat dinikmati hingga kini.

\section{Belajar Seumur Hidup (Life Long Learning)}

Pendidikan pada dasarnya secara konseptual dan praksis adalah proses memfasilitasi seseorang untuk mencari dan menemukan pengetahuan dan juga keterampilan yang dibutuhkan dalam kehidupannya melalui proses belajar. Hal ini mengindikasikan bahwa semua kegiatan dan aktivitas manusia berpotensi dipergunakan untuk belajar sekaligus sebagai sarana atau media pembelajaran.

Proses belajar tersebut idealnya berlangsung seumur hidup atau sepanjang hayat (life long learning, al-ta'allum madâ al-hayâh). Hal ini memberikan arti bahwa belajar dapat dilakukan seumur dan sepanjang kehidupan seorang pembelajar; dapat dilakukan dari siapa saja (sumber belajar), kapan saja (waktu belajar, dan di mana (tempat belajar) saja serta oleh diri dan terutama saat menghadapi generasi digital.

Menurut Grafura dan Wijayanti (2019, hlm. 18-26), generasi digital memiliki beberapa kelebihan yang harus dimanfaatkan dan kelemahan yang harus diwaspadai. 
Kelebihan generasi digital antara lain sangat peduli terhadap identitas diri, memiliki semangat ingin mengetahui banyak hal, multitasking serta ide dan gagasannya melampaui kita. Sedangkan kelemahan generasi digital adalah mudah menyerah dan putus asa, tidak mempunyai filter dalam mengakses informasi, dan kurang memiliki kepekaan sosial.

Belajar seumur hidup (life long learning, al-ta'allum madâ al-hayâh) adalah pembelajaran yang berlangsung secara terus-menerus dan berkesinambungan (continuing learning) semenjak lahir di buaian sampai akhir hayat sebelum menghembuskan nafas terakhir kehidupan.

Belajar sepanjang hayat atau pendidikan seumur hidup (life long education) adalah asas konsep belajar yang selaras bagi orang-orang yang hidup dalam dunia modern transformasi dan informasi seperti era 4.0; di mana setiap pembelajar harus lebih adaptif dan kreatif dalam menyesuaikan diri secara terus-menerus dengan situasi yang baru dan perkembangan mutakhir sesuai dengan realitas kontemporer yang sering kali berlangsung sangat dinamis dan cepat.

Sebagai continuing learning, life long learning merupakan konsep pendidikan yang tidak mengenal istirahat. Kondisi ini menuntut adanya kesabaran tingkat tinggi. Hal ini telah dibuktikan oleh generasi kaum Muslimin terutama oleh para ulamanya seperti yang terekam dalam karya fenomenal berjudul Shafahât min Shabr Al-'Ulamâ' (Abdul Fattah, 2019).

\section{Kesadaran Pendidikan}

Selain berimplikasi pada tekad baja dalam belajar dan belajar seumur hidup, heutagogi juga seharusnya memberikan kesadaran kepada pembelajar tentang kesadaran pendidikan.

Qomar (2013, hlm. 2) menyatakan bahwa agar pendidikan Islam maju, bermutu atau berkualitas secara realitas, setidaknya harus ditemukan tiga kunci pembukanya dan dipakai sebagai resep untuk meraih kemajuannya. Kunci yang dimaksud berupa epistemologi pendidikan Islam, manajemen pendidikan Islam, dan kesadaran pendidikan.

Ketiga kunci tersebut oleh Qomar (2014, hlm. 141) dinyatakan sebagai strategi atau tiga langkah mendasar untuk memajukan pendidikan Islam dalam menghadapi era globalisasi yang seharusnya mendapat perhatian para pemikir, penentu kebijakan, praktisi, dan manajer atau pemimpin lembaga pendidikan Islam (Maya dan Lesmana, 2018, hlm. 295).

Yang dimaksud dengan kesadaran pendidikan sendiri menurut Qomar (2012, hlm. 120) adalah kehadiran sikap mengetahui, memahami, menginsafi, dan menindaklanjuti 
proses pembimbingan untuk mengembangkan potensi kemampuan seseorang menjadi sumber daya manusia yang kuat (strong human resources).

Bagi siswa atau pembelajar, kesadaran pendidikan terekspresi pada kesadarannya bahwa tugas utamanya adalah belajar sehingga mendorongnya untuk mengisi waktu dalam jumlah dominan dengan kegiatan belajar. Kegiatan belajar atas inisiatif dari siswa sendiri, tanpa tekanan dan pengondisian dari pihak lain. Kegiatan belajar didasarkan rasa ingin menggeser atau menghilangkan kebodohan dan diganti dengan kepandaian, wawasan luas, dan pemahaman yang mendalam, bukan karena intervensi politik, tuntutan pasar, keranjingan gelar, dan kedudukan dalam jabatan (Qomar 2012, hlm. 121122).

\section{E. Integrasi Heutagogi dalam Konsep Pedagogi-Andragogi}

Dalam praktik pendidikan Islam, pembelajaran atau proses belajar dikenal dengan term mencari ilmu (thalab al-'ilm), di mana ilmu sendiri secara umum sering didefinisikan sebagai proses mengetahui hakikat substansial dari sesuatu secara pasti (idrâk al-syai' 'alâ haqîqatihi idrâkan jâziman).

Berdasarkan definisi terminologis-filosofis dari ilmu dan praktik pembelajaran dan pendidikan dalam Islam sepanjang sejarahnya, Islam tidak membedakan proses belajar bagi anak-anak (pedagogi) dan orang dewasa (andragogi) secara konseptual, kecuali dalam hal yang bersifat faktual-praksis yang terkait dengan fase perkembangan dan kebutuhan masing-masingnya secara gradualistik.

Sehingga makna pendidikan yang integral menurut Abd. Rachman Assegaf (2019, hlm. 182) adalah pendidikan yang bukan hanya transfer of knowledge dan transfer of methodology (aplikasi metodologi), melainkan juga transfer of values (internalisasi nilai). Makna pendidikan hakikatnya adalah menyeimbangkan antara belajar untuk tahu (learning to know), belajar untuk berbuat (learning to do), belajar untuk menjadi (learning to be), dan belajar untuk hidup bersama (learning to live together).

Masih menurut Assegaf, upaya mempertemukan pendekatan pedagogi dengan andragogi akan berdampak positif bagi pengembangan pendidikan Islam yang sampai sekarang masih dominan mengajar (teaching), sementara pembelajaran (instruction) dan pendidikan (education) dalam praktiknya belum dilaksanakan secara optimal. Integrasi andra-pedagogi diharapkan dapat mengatasi keterbatasan dalam praktik pendidikan Islam tersebut (2019, hlm. 182).

Itu baru integrasi antara pedagogi dan andragogi. Bagaimana bila kedua konsep pendidikan dan pendekatan pembelajaran tersebut diintegrasikan dengan heutagogi? Tentu dari integrasi pedagogi-heutagogi, andragogi-heutagogi, atau integrasi pedagogiandragogi-heutagogi dapat diharapkan untuk memaksimalkan praktik pendidikan Islam 
sebagaimana yang dimaksud, yaitu menyeimbangkan berbagai aspek dan tujuan pendidikan. Praktik pendidikan Islam yang lebih maksimal tersebut tentunya ditopang oleh tekad baja dalam belajar, belajar seumur hidup, dan karena adanya kesadaran pendidikan.

\section{Kesimpulan}

Berdasarkan paparan pembahasan dan uraian analisisnya sebagaimana tersebut di atas, dapat disimpulkan bahwa konsep pedagogi, andragogi, dan heutagogi merupakan suatu kontinum yang tidak berdiri sendiri; di mana heutagogi dinyatakan sebagai kelanjutan dari konsep andragogi. Konsep heutagogi yang selaras dengan konsep mencari ilmu (thalab al-'ilm) dalam pendidikan Islam merupakan model pembelajaran mandiri atau pembelajaran oleh/untuk diri sendiri pembelajar untuk memperoleh ilmu pengetahuan dan mendapatkan keterampilan. Dalam pembahasan artikel ini disimpulkan bahwa dalam pendidikan Islam kontemporer konsep heutagogi memiliki implikasi edukatif yang relevan, meliputi tekad baja ('uluww al-himmah) dalam belajar (thalab al-'ilm), belajar sepanjang hidup (life long learning, al-ta'allum madâ al-hayâh), kesadaran pendidikan, dan integrasi heutagogi ke dalam konsep pedagogi-andragogi. Semua implikasi edukatif dari heutagogi tersebut diharapkan mampu memaksimalkan praktik pendidikan Islam, terutama dalam menyeimbangkan berbagai aspek dan tujuannya.

\section{Daftar Pustaka}

Al Farabi, M. (2018). Pendidikan Orang Dewasa dalam Al-Qur'an. Kencana (Prenadamedia Group).

Al-'Affânî, S. I $\underline{\mathrm{H}}$. (1997). Shalâh Al-Ummah fî 'Uluww Al-Himmah. Mu'assasah Al-Risâlah.

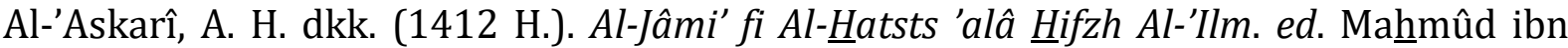
Muhammad Al-haddâd. Maktabah Ibn Taimiyyah dan Maktabah Al-'Ilm Jeddah.

Al-'Imrân, 'A. i. M. (1422 H.). Al-Musyawwiq ilâ Al-Qirâ'ah wa Thalab Al-'Ilm. Dâr 'Âlam AlFawâ'id.

Al-Hamad, M. B. I. (2014). Mental Juara: 50 Faktor Pendukung Mentalitas Muslim Juara. Pustaka Imam Asy-Syafi'i.

Al-Muqaddam, M. i. I. (t.t.). 'Uluww Al-Himmah. Dâr Ibn Al-Jauzî.

Al-Sirjani, R. (2016). Sumbangan Peradaban Islam pada Dunia. Pustaka Al-Kautsar.

Al-Zahrânî, M. i. M. (2005). Min Hady Al-Salaf fi Thalab Al-'Ilm. Dâr Thayyibah.

Assegaf, A. R. (2019). Ilmu Pendidikan Islam: Madzhab Multidisipliner. PT RajaGrafindo Persada.

Bunyamin. (2010). Hakekat Manusia Sebagai Animal Educandum, Educabili, dan Educator dalam Perspektif Islam. Reforma: Jurnal Ilmiah Kajian Ilmu-ilmu Agama Islam, 1(IX). Danim, S. (2015). Pedagogi, Andragogi, dan Heutagogi. CV Alfabeta.

Fattah, A. (2019). Kisah-kisah Kesabaran Para Ulama: Menelusuri Pahit-Getirnya 
Perjalanan Hidup Manusia Shalih dalam Mencari Ilmu. Zamzam.

Grafura, L. \& Wijayanti, A. (2019). Spirit Pedagogi di Era Disrupsi. Laksana.

Hasbullah. (2017). Dasar-dasar Ilmu Pendidikan. PT RajaGrafindo Persada.

Khoeriyah, M. (2019). Heutagogy in The Course of Pesantren Education (Case Study at Pesantren Salaf Al-Luqmaniyyah). International Journal on Islamic Educational Research, 3(1).

Latip, A. (2020). Peran Literasi Teknologi Informasi dan Komunikasi pada Pembelajaran Jarak Jauh di Masa Pandemi Covid-19. EduTeach: Jurnal Edukasi dan Teknologi Pendidikan, 1(2).

Mariah H., S. (2015). Membangun Revolusi Berpikir Mahasiswa PLS Melalui Pendekatan Heutagogi. Jurnal Handayani, 4(1).

Marzuki, M. S. (2012). Pendidikan Nonformal: Dimensi dalam Keaksaraan Fungsional dan, Pelatihan, dan Andragogi. PT Remaja Rosdakarya.

Maya, R. dan Lesmana, I. (2018). Pemikiran Prof. Dr. Mujamil Qomar Tentang Manajemen Pendidikan Islam. Islamic Management: Jurnal Manajemen Pendidikan Islam, 01(02).

Maya, R. dan Syafri, U. A. (2020). Spirit Literasi Perspektif Al-Muqaddam: Analisis Model Berliterasi Muhammad ibn Ismâ'îl Al-Muqaddam. Edukasi Islami: Jurnal Pendidikan Islam, 09(01).

Mulyadi, S., Basuki, A.M. Heru, dan Rahardjo, W. (2017). Psikologi Pendidikan: Dengan Pendekatan Teori-teori Baru dalam Psikologi. PT RajaGrafindo Persada.

Purwanto, A., dkk. (2020). Studi Eksploratif Dampak Pandemi COVID-19 Terhadap Proses Pembelajaran Online di Sekolah Dasar. EduPsyCouns Journal, 2(1).

Qomar, M. (2012). Kesadaran Pendidikan: Sebuah Penentu Keberhasilan Pendidikan. ArRuzz Media.

Qomar, M. (2013). Strategi Pendidikan Islam. Penerbit Erlangga.

Qomar, M. (2014). Menggagas Pendidikan Islam. PT Remaja Rosdakarya.

Ramayulis. (2015). Dasar-dasar Kependidikan: Suatu Pengantar Ilmu Pendidikan. Kalam Mulia.

Rosidin. (2013). Konsep Andragogi dalam Al-Qur'an: Sentuhan Islami pada Teori dan Praktik Pendidikan Orang Dewasa. Litera Ulul Albab.

Subbekan, N. (2019). Heutagogi dalam Al-Qur'an (Kajian Surat Al-'Alaq Ayat 1-5). Skripsi. Program Studi Ilmu Al-Qur'an dan Tafsir Fakultas Ushuluddin dan Filsafat Universitas Islam Negeri (UIN) Sunan Ampel Surabaya.

Sulistya, R. (2019). Heutagogi Sebagai Pendekatan Pelatihan Bagi Guru di Era Revolusi Industri 4.0. Jurnal Pendidikan dan Kebudayaan, 4(2). 